\title{
Professional values and Burnout among nurses
}

\author{
Naglaa A Abdalla, Hala R yousef \& Sahar M Morsy. \\ Nursing specialist, Technical Institute of Nursing, Assiut University Egypt. \\ Professor of Nursing Administration, Faculty of nursing, Assuit University Egypt. \\ Assistant Professor of Nursing Administration, Faculty of nursing, Assuit University Egypt.
}

\begin{abstract}
Nurses' professional values play an important role in the degree of burnout that the nurses may expose in their workplace. This study aimed to find out the relationship between professional values and burnout among nurses. Methods: research design: Descriptive correlational research design. Setting: this study carried out at the main Assiut University Hospital. Subjects: The sample consists of 479 nurses working in Assuit University hospital in general and specialized medical, surgical and intensive care units. Tools of study: The study tools consisted of three tools which included: Demographic data sheet, Nurses Professional Values Scale, and Maslach's Burnout Inventory scale. Results: A High percent of the studied nurses reported that professional values were the most important in nursing practice. A High percent of the studied nurses who graduated from the secondary technical school of nursing had high level of burnout. Conclusion: There was a positive correlation between nurses' professional values and burnout. Recommendation: Generalization of Egyptian Code of Ethics for Nursing Profession to all governmental and private hospitals at Egypt and Providing adequate staffing and flexible scheduling for nurses to suite the personal and social stabilization through regulating the rotating shift.
\end{abstract}

Key words: Professional values, Burnout \& Nurses.

\section{Introduction}

Nursing is a profession in which nurses make decisions that affect the health of patients. The health care environment in which nurses work is more complex than ever. There are a lot of factors contributing to this environment such as the nursing shortage, advanced technology, managed care, and diverse patient populations (Leners et al., 2006).Professional values include respect for human dignity, protection of patient privacy, protection from harm, personal and professional responsibility and accountability maintain competence in the area of practice and improve the standard of patient care (Fahrenwald et al., 2005).

Nurses' professional values are important because they affect the decisions made in caring for patients (Butts \& Rich, 2008). Nurses need to be aware of their professional values and at the same time be able to care for patients who have different values (Blais et al., 2006). An awareness of professional values, cultural differences, and bases help to avoid ineffective communication in stressful situations. Preventing burnout requires many of the same coping skills that we use to combat reactions to any stressor and reduce burnout (Altun, 2002).

Burnout is "an experience of physical, emotional, and mental exhaustion, caused by long-term involvement in situations that are emotionally demanding." It may manifest as depersonalization, low productivity, and feelings of low achievement. Burnout results from the accumulation of stress that exhausts individuals to the point where their energy resources are insufficient for their attempts to survive the pressure of a situation (Maslach et al., 2005).

\section{Significance of the study}

Nurses' professional values play an important role in the degree of burnout they experience, because it influences the person's behaviors, both consciously and unconsciously. A well-formed value system helps to reduce conflict in the decision-making process.

Studying nurses' professional values is very important because of its negative consequences on nurses, patient, and organization so the awareness of personal beliefs, values, helps to avoid ineffective communication in stressful situations preventing burnout.
Aims of the study
General objectives
- Find out the relationship between professional values and burnout among nurses at the main Assiut University Hospital.
Specific objectives
- Explore the professional values of nurses.
- Determine degree of burnout among nurses. 


\section{Subject \& Methods}

The methodology pursued in the conduction of the study portrayed according to the following designs

- Technical design

- Administrative design

- Operational design

- Statistical design

- Technical design

This design involves the research design, setting, subject, and tools of data collection.

\section{Research design}

The descriptive correlational research design was used in this study.

\section{Setting}

The present study was carried out at the main Assiut University Hospital in general and specialized medical, surgical and intensive care units.

\section{Subjects}

The sample consists of all nurses working in the main Assuit University Hospital in medical, surgical and intensive care units, they were 479. Medical units $(n=153)$, surgical units $(n=162)$, and ICU $(n=164)$.

Tools of data collection.

This study consists of three tools which included:

$1^{\text {st }}$ Demographic data sheet:

It was designed to collect personal data about nurses' work setting, residence, gender, and years of experience, marital status, and level of education.

$2^{\text {nd }}$ Tool Nurses Professional Values Scale (NPVS)

Nurses Professional Values Scale (NPVS) adopted from Americian nurses association (ANA) Code of Ethics for Nurses (1985) and translated by the investigator. It used to assess nurses professional values. It includes 42 statements of expression point of view instead of 44 statements (there is two statements excluded from the scale participate in peer review_ Use guidelines to determine the appropriateness of research).

This tool has 11 subscales.(Human dignity, Privacy, Safeguard client, Responsibility, and accountability, Competence, Informed judgment, Contributes to knowledge, Improve standards, Conditions of employment, Maintain integrity and Collaborate).

The scoring was on a three-point likert scale (not important (0) _important(1) _ very important(2)).

$3^{\text {rd }}$ Tool Maslach's Burnout Inventory scale.

Maslach's Burnout Inventory developed by Maslach and Jackson, 1997 to assess the degree of burnout among nurses. It consists of 22 statements covering three subscales:

- Emotional exhaustion consists of (8) statement measuring nurses perception of being used up, frustrated, tired or stressed.

- Depersonalization consists of (8) statement pertaining nurses perceptions of treating others impersonally, and becoming callous and/or hardened emotionally.

- Personal achievement consists of (6) statement) measuring nurses perception of having an influence on others, working well with others, and dealing well with patients and with problems.

- The scoring was on a three-point likert scale (not important (0)_important(1) _ very important(2)).

Professional values scoring system

If the score ranges from (0-42) the level of professional values will be considered low; and if the score ranges from (43- 84) the level of professional values will be considered moderate; and if the score ranges from (85-126) the level of professional values will be considered high.

\section{Burnout scoring system}

If the score ranges from (0-22) the level of burnout will be considered low; and if the score ranges from (23- 44) the level of burnout will be considered moderate; and if the score ranges from (45-66) the level of burnout will be considered high.

\section{Administrative design}

An official litter approval obtained from the Dean of the faculty of nursing, Assiut University to the General Manager of Assiut university hospital to conduct the study. The litter included permission to carry out the study and explained the purpose and nature of the study.

Operational design

Preparatory phase

This phase started from October to December 2014 and included the following:

1-Reviewing the available literature concerning the topic of the study.

2-Preparing and translating the tools of the study.

The study tools were developed by the researcher, revised by the supervisors and experts in the field of research. The validity was done for tools (I\&II) by five experts in administration field

Pilot study

A pilot study carried out to assess clarity and applicability of the tools and to identify the problems that may be encountered during the actual data collection. It was applied to forty-five nurses (10\% of the sample) from the hospital that included the main subjects of the study. Departments and nurses for pilot study were selected randomly. Departments included in the pilot study were (medical units, tropical units, surgery, urology, general intensive care unit, trauma intensive care unit).data collected from pilot study was analyzed; their reliability was assessed using Cronbach's alpha coefficient method. This turned to be $(\alpha$ 0.94) for nursing professional values; $(\alpha$ 0.94) for the level of burnout. Thus indicate a high degree of reliability for study tools. 
The sample of the pilot study was included in the total sample because no modification has been made.

\section{Data collection}

Field work

The researcher started to collect data from first of October 2014, until the end of January 2015. The interview occurred at nurse's room in every department in the main Assiut University Hospital. Each interview took about 15-20 minutes to fill the questionnaire. Throughout the interview, every answer from the nurses recorded according to designed question in the form, followed by correction and explanation for every wrong answer. Every day from 10 to 15 interviews of forms finished, interviews done at morning, afternoon, or night shift.

\section{Ethical considerations}

An oral consent taken from the nurses who agreed to participate in the study after a full explanation about the purpose of the study and they assured that the information obtained will be used only for the purpose of the study and it will be confidential.

\section{Statistical design}

The obtained data reviewed, prepared for computer entry, coded, analyzed, and tabulated. Descriptive statistics (frequencies, percentage, mean, and standard deviation) done using computer program SPSS version 19.Chi-square test used to compare differences in the distribution of frequencies between different groups. It considered significant when Pvalues were less than 0.05 .

\section{Results}

Table (1): Demographic characteristics of studied nurses at the main Assiut University Hospital (No. = 479).

\begin{tabular}{|c|c|c|}
\hline Demographic characteristics & Frequency & Percent \\
\hline \multicolumn{3}{|l|}{ I-work setting } \\
\hline Medical. & 153 & 31.9 \\
\hline Surgical. & 162 & 33.8 \\
\hline I.C.U. & 164 & 34.2 \\
\hline \multicolumn{3}{|l|}{ II-Residence } \\
\hline Urban. & 263 & $\underline{54.9}$ \\
\hline Rural. & 216 & 45.1 \\
\hline \multicolumn{3}{|l|}{ III-Gender } \\
\hline Male. & 77 & 16.1 \\
\hline Female. & 402 & $\underline{83.9}$ \\
\hline \multicolumn{3}{|l|}{ IV-Years of experience } \\
\hline $0->5$ years. & 108 & 22.5 \\
\hline 5->10 years. & 115 & 24.0 \\
\hline $10->15$ years. & 99 & 20.7 \\
\hline$>15$ years. & 157 & $\underline{32.8}$ \\
\hline \multicolumn{3}{|l|}{ V-Marital status } \\
\hline Single. & 101 & 21.1 \\
\hline Married. & 370 & $\underline{77.2}$ \\
\hline Widowed/Divorced. & 8 & 1.7 \\
\hline \multicolumn{3}{|l|}{ VI-Educational qualification } \\
\hline Secondary technical school of nursing. & 325 & $\underline{67.8}$ \\
\hline Technical institute of nursing. & 82 & $\overline{17.1}$ \\
\hline Baccalaureate degree of nursing science. & 72 & 15.0 \\
\hline
\end{tabular}


Table (2): Levels of professional values in accordance with demographic characteristics as reported by studied nurses $($ No. $=479)$.

\begin{tabular}{|c|c|c|c|c|c|c|c|}
\hline \multirow{3}{*}{ Demographic characteristics } & \multicolumn{6}{|c|}{ Nursing professional Values } & \multirow{3}{*}{ P. value } \\
\hline & \multicolumn{2}{|c|}{ Low $(n=5)$} & \multicolumn{2}{|c|}{ Moderate $(n=87)$} & \multicolumn{2}{|c|}{ High $(n=387)$} & \\
\hline & No. & $\%$ & No. & $\%$ & No. & $\%$ & \\
\hline \multicolumn{8}{|l|}{ I-Work setting } \\
\hline Medical. & 3 & 60.0 & 18 & 20.7 & 132 & 34.1 & \multirow{3}{*}{$0.040^{*}$} \\
\hline Surgical. & 1 & 20.0 & 29 & 33.3 & 132 & 34.1 & \\
\hline I.C.U. & 1 & 20.0 & 40 & 46.0 & 123 & 31.8 & \\
\hline \multicolumn{8}{|l|}{ II-Residence } \\
\hline Urban. & 4 & 80.0 & 34 & 39.1 & 225 & 58.1 & \multirow{2}{*}{$0.003 * *$} \\
\hline Rural. & 1 & 20.0 & 53 & 60.9 & 162 & 41.9 & \\
\hline \multicolumn{8}{|l|}{ III-Gender } \\
\hline Male. & 0 & 0.0 & 9 & 10.3 & 68 & 17.6 & \multirow{2}{*}{0.156} \\
\hline Female. & 5 & 100.0 & 78 & 89.7 & 319 & 82.4 & \\
\hline \multicolumn{8}{|l|}{ IV-Years of experience } \\
\hline $0->5$ years. & 0 & 0.0 & 20 & 23.0 & 88 & 22.7 & \multirow{4}{*}{0.448} \\
\hline 5->10 years. & 0 & 0.0 & 24 & 27.6 & 91 & 23.5 & \\
\hline $10->15$ years. & 2 & 40.0 & 19 & 21.8 & 78 & 20.2 & \\
\hline$>15$ years. & 3 & 60.0 & 24 & 27.6 & 130 & 33.6 & \\
\hline \multicolumn{8}{|l|}{ V-Marital status } \\
\hline Single. & 0 & 0.0 & 23 & 26.4 & 78 & 20.2 & \multirow{3}{*}{0.510} \\
\hline Married. & 5 & 100.0 & 63 & 72.4 & 302 & 78.0 & \\
\hline Widowed/Divorced. & 0 & 0.0 & 1 & 1.1 & 7 & 1.8 & \\
\hline \multicolumn{8}{|l|}{ VI-Educational Qualification } \\
\hline Secondary technical school of nursing. & 5 & 100.0 & 77 & 88.5 & 243 & 62.8 & \multirow{3}{*}{$0.001 * *$} \\
\hline Technical institute of nursing. & 0 & $\mathbf{0 . 0}$ & 6 & 6.9 & 76 & 19.6 & \\
\hline Baccalaureate degree of nursing science. & 0 & 0.0 & 4 & 4.6 & 68 & 17.6 & \\
\hline
\end{tabular}

$*$ Statistically significant differences $P<0.05$

Table (3): Analysis of variance in levels of burnout of nurses according to demographic characteristics $($ No. $=$ 479).

\begin{tabular}{|c|c|c|c|c|c|c|c|}
\hline \multirow{3}{*}{ Demographic characteristics } & \multicolumn{6}{|c|}{ Levels of Burnout } & \multirow{3}{*}{ P. value } \\
\hline & \multicolumn{2}{|c|}{ Low $(n=36)$} & \multicolumn{2}{|c|}{ Moderate $(n=171)$} & \multicolumn{2}{|c|}{ High $(n=272)$} & \\
\hline & No. & $\%$ & No. & $\%$ & No. & $\%$ & \\
\hline \multicolumn{8}{|l|}{ I-Department } \\
\hline Medical units. & 12 & 33.3 & 50 & 29.2 & 91 & 33.5 & \multirow{3}{*}{0.055} \\
\hline Surgical units. & 18 & 50.0 & 52 & 30.4 & 92 & 33.8 & \\
\hline I.C.U. & 6 & 16.7 & 69 & 40.4 & 89 & 32.7 & \\
\hline \multicolumn{8}{|l|}{ II-Residence } \\
\hline Urban. & 22 & 61.1 & 100 & 58.5 & 141 & 51.8 & \multirow{2}{*}{0.290} \\
\hline Rural. & 14 & 38.9 & 71 & 41.5 & 131 & 48.2 & \\
\hline \multicolumn{8}{|l|}{ III-Gender } \\
\hline Male. & 7 & 19.4 & 27 & 15.8 & 43 & 15.8 & \multirow{2}{*}{0.849} \\
\hline Female. & 29 & 80.6 & 144 & 84.2 & 229 & 84.2 & \\
\hline \multicolumn{8}{|l|}{ IV-Years of experience } \\
\hline $0->5$ years. & 7 & 19.4 & 34 & 19.9 & 67 & 24.6 & \multirow{4}{*}{$0.044 *$} \\
\hline 5->10 years. & 3 & 8.3 & 38 & 22.2 & 74 & 27.2 & \\
\hline $10->15$ years. & 7 & 19.4 & 40 & 23.4 & 52 & 19.1 & \\
\hline$>15$ years. & 19 & 52.8 & 59 & 34.5 & 79 & 29.0 & \\
\hline
\end{tabular}




\begin{tabular}{|c|c|c|c|c|c|c|c|}
\hline \multicolumn{8}{|l|}{ V-Marital status } \\
\hline Single. & 4 & 11.1 & 37 & 21.6 & 60 & 22.1 & \multirow{3}{*}{0.375} \\
\hline Married. & 31 & 86.1 & 133 & 77.8 & 206 & 75.7 & \\
\hline Widowed/Divorced. & 1 & 2.8 & 1 & 0.6 & 6 & 2.2 & \\
\hline \multicolumn{8}{|l|}{ VI-Educational Qualification } \\
\hline Secondary technical school of nursing. & 25 & 69.4 & 130 & 76.0 & 170 & 62.5 & \multirow{3}{*}{$0.046^{*}$} \\
\hline Technical institute of nursing. & 5 & 13.9 & 20 & 11.7 & 57 & 21.0 & \\
\hline Baccalaureate degree of nursing science. & 6 & 16.7 & 21 & 12.3 & 45 & 16.5 & \\
\hline
\end{tabular}

*Statistically significant differences $P<0.05$

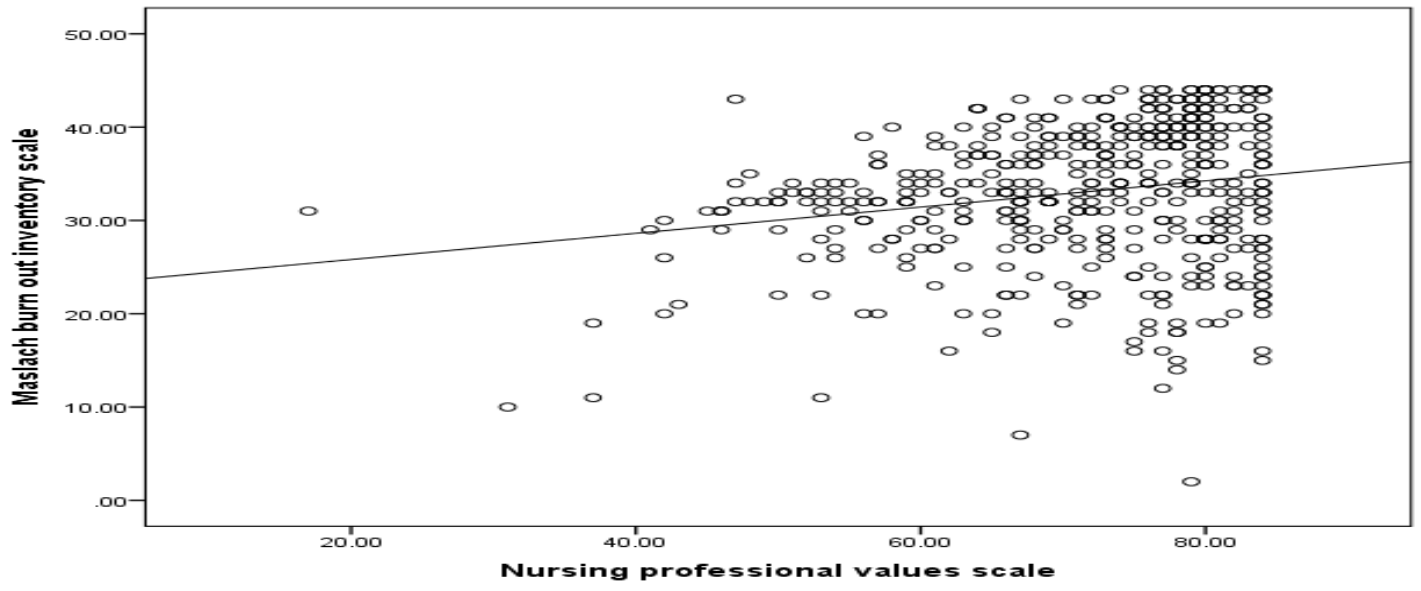

Figure (1): Correlation between professional values and burnout among studied nurses at the main Assiut University Hospital (No. = 479).

Table (1): shows that high percent of studied nurses were female, married and graduated from the secondary technical school of nursing $(83.9 \%, 77.2 \%$ and $67.8 \%$ ) respectively. More than half of them living in urban areas (54.9\%). Above one-third of them, their years of experience were more than fifteen years and working in intensive care units (34.8\% and $32.8 \%)$ respectively.

Table (2): demonstrates that there were statistically significant relation among the studied nurses as regards to the work setting, residence, and educational qualification. This table illustrates that $(60 \%)$ of the studied nurses working in medical units have low professional values while $(20.1 \%)$ of the studied nurses working in surgical units and intensive care units have low professional values.

As regards to residence $(80 \%)$ of the study sample living in urban areas have low professional values while $(20.1 \%)$ of the studied nurses living in rural areas have low professional values.

As regards to educational qualification $(100 \%)$ of the studied nurses graduated from the secondary technical school of nursing have low professional values while $(0.0 \%)$ of the studied nurses graduated from technical institute and faculty of nursing have low professional values.
Table (3): shows the levels of burnout in accordance with demographic characteristics. As the table, there were statistically significant differences among the studied nurses as regards to years of experience and educational qualification. This table illustrates that $(52.8 \%)$ of the studied nurses their years of experience more than fifteen years have a low level of burnout while $(8.3 \%)$ of them having from five to ten years of experience have a low level of burnout.

As regards to educational qualification $(76 \%)$ of the studied nurses graduated from nursing schools have a moderate level of burnout, while (11.7\%) of the study sample graduated from the technical institute have moderate levels of burnout.

Figure (1): demonstrates that there was a highly positive statistically significant correlation between professional values and burnout among studied nurses working in medical, surgical and intensive care units.

\section{Discussion}

The finding of the present study showed that high percent of studied nurses were females, married and graduating from the secondary technical school of nursing. This finding might be attributed to the fact that the majority of nurses who graduated from the 
secondary technical school of nursing were female. This supported by Walling, (2011) who mentioned that the proportion of men entering the nursing profession has been growing but it remains a femaledominated occupation.

This finding was consistent with Fagan, (2006) who conducted a study in California (USA) state University about ethical changes in the nursing students and found that the majority of participants were female. Also consistent with Parvan et al., (2012) who conducted the study in Tabriz University of Medical Science, Iran, about personal values and work satisfaction among hospital staff, and his finding revealed that the majority of the subjects were also female.

Concerning to years of experience, the present finding showed that high percent of studied nurses having more than 5 years' experience. This finding might be attributed to new graduate nurses change their career by completing another study to be appointed in another place inside their hospital. Other nurses choose to travel abroad because of unsuitable working condition and inadequate salaries.

These findings are consistent with Gass, (2010) who conducted a study in Codon University, about the knowledge and attitudes of mental health nurses to ethical electro-convulsive therapy, who found the majority of respondents, had more than 5 years' experience. And also consistent with McNutt, (2008) who mentioned that if a nurse is unhappy in a certain hospital or community because of compensation and management; she will look for a place that will provide her with benefits she deserves.

In the present study, there are some differences in the levels of professional values in accordance with the demographics characteristics. These differences are regarding work setting and educational qualification. In which the high percent of the studied nurses who working in the intensive care units scored high level of professional values. And high percent of the studied nurses graduated from the secondary technical school of nursing scored high level of professional values. This finding was consistent with Debra et al., (2009), who found that associate degree student had better knowledge about professional values than the baccalaureate degree students.

In the present study, there was statistically significant difference in the levels of burnout and demographics characteristics in relation to educational qualification. In which high percent of the studied nurses graduated from secondary technical school of nursing scored high level of burnout. This finding was in line with Abd El Rahman, (1997) who conducted study at Assiut University Hospital about burnout among nurses; found that nurses graduated from the secondary technical school of nursing scored high level of burnout.

In the present study professional value and burnout were positively correlated in all work setting. This may because professional value consists of beliefs, attitudes, and feelings which guide nurses' decisions and actions. And the nurses who had high professional value become more responsible, safeguard patient, improve the standard of care and maintain competence in their area of practice and this add stressors for nurses and may lead to burnout.

This finding was consistent with the findings of Altun, (2002) who found that the professional value of nurses played an important role in the level of burnout. Also consistent with Liselotte et al., (2010) who concluded that professional value is determined by job burnout and found that nursing students with burnout were more likely to engage in unprofessional behaviors than those without burnout. And consistent with Fang Cheng et al., (2015) who conducted a study about the correlation between burnout and professional value in Chinese oncology nurses, found that professional value and burnout were positively correlated.

\section{Conclusion}

Based on the results of the present study, it can be concluded that

- A high percent of the studied nurses reported that professional values were most important in nursing practice.

- Nurses who graduated from the secondary technical school of nursing had a high level of burnout.

- There was a positive correlation between nurses' professional values and burnout.

\section{Recommendations}

Based on results of the present study it can be recommended that:

Promotion of professional values for all nurses categories through

- Generalization of Egyptian Code of Ethics for Nursing Profession to all governmental and private hospital at Egypt.

- Hospitals should reinforce the professional values in new nurses through implementing orientation program to elevate their information level regarding Code of Ethics.

Reducing burnout among all nursing categories through

- Managers should carefully identify factors that cause burnout and implement policies that will reduce and manage it. 
- Nurses should be encouraged to attend workshops to enhance their skills and learn new things to reduce the level of stress and burnout.

- Regular staff meeting this allows the staff member to express their feeling and get feedback.

- Enforcing break time away from the units to reduce stress by providing a quiet time away from patients and their families.

\section{References}

1. Abd El Rahman S., (1997): A study of Burnout among Nurses at Assiut University hospital, Unpublished Master Thesis, Assiut University.

2. Altun I., (2002): Burnout and nurses personal and professional values. Nurs Ethics, volume9, issue 3, p 269 Correlation between burnout and professional value in Chinese oncology nurses: A questionnaire survey

3. Blais K., Hayes J., Kozier B., \& Erb G., (2006): Professional nursing practice: Concepts and perspectives, New Jersey, $5^{\text {th }}$ ed, Pp 31-35.

4. Butts J., \& Rich K., (2008): Nursing ethics across the curriculum and into practice, New York, $2^{\text {nd }}$ ed, p. 48.

5. Cheng F., Meng A., \& Jin T., (2015): Correlation between burnout and professional value in Chinese oncology nurses: a questionnaire survey. Int J Nurs Sci, Available @ http://dx.doi.org/10.1016/j.ijnss.2015.04.004.

6. Debra K., (2009): Professional values: A study of education and experience in nursing students and nurses, Journal of nursing, Volume3, issue6, Pp 1183-1191.

7. Fahrenwald N., Basset S., Tschetter L., Carson P., White L., \& Winterboer V., (2005): Teaching core nursing values. Journal of professional nursing. volume 21 , issue 1, Pp 4561.

8. Fagan J., (2006): Ethical changes in the nursing student. College of Health and Human Services California State University, Journal of Health management, volume 1, Pp 1-7

9. Gass A., \& John P., (2010): the knowledge and attitudes of mental health nurses to electroconvulsive therapy, Journal of Advanced Nursing, volume 27, Pp 83-90.

10. Leners D., Roehrs C., \& Piccone A., (2006): Tracking the development of professional values in undergraduate nursing students. Journal of Nursing Education, volume 45, issue12, Pp 504511.

11. Liselotte N., Massie F., \& Eacker A., (2010): Correlation between burnout and professional conduct and attitudes among US medical students. JAMA, volume304, issue11, P 1173.
12. Maslach C., \& Leiter M., (2005): Stress and burnout: The critical research. In C. L. Cooper (Ed.), Handbook of stress medicine and health, $2^{\text {nd }}$ ed, London, Pp 153-170.

13. McNutt B., (2008): What Causes Nurses to Quit? Available @ http: //ezinearticles. Com/? What Causes Nurses to Quit? \&id1416683

14. Parvan K., Zamanzadeh. V., \& Hosseini F., (2012): Nursing students' perspectives on professional values in the universities of medical sciences in Iran, International Research Journal of Applied and Basic Sciences. Volume 3, issue 6, Pp 1183-1191, 2012. Journal for Nurses in Staff Development. volume15, issue5, Pp 185192.

15. Willing P., (2011): How did Nursing Become a Female profession available @ http://www? The male-nurse. Com /2011/ 06/ how-did-nursingbecome-female.html. 